\title{
Cladding of Advanced Al Alloys Employing Friction Stir Welding
}

\author{
A.A. van der Stelt ${ }^{1,2, a}$, T.C. Bor ${ }^{2, b}$, H.J.M. Geijselaers ${ }^{2, c}$, \\ R. Akkerman ${ }^{2}$, A.H. van den Boogaard ${ }^{2}$ \\ ${ }^{1}$ Materials innovation institute (M2i), PO Box 5008, 2600 GA Delft, the Netherlands \\ ${ }^{2}$ Engineering Technology, University of Twente, PO Box 217, 7500 AE Enschede, the Netherlands \\ aa.vanderstelt@m2i.nl, bt.c.bor@utwente.nl, ch.j.m.geijselaers@utwente.nl
}

Keywords: Friction surface cladding, friction stir welding, friction surfacing, AA2024 aluminium alloy, AA1050 aluminium alloy

\begin{abstract}
In this paper an advanced solid state cladding process, based on Friction Stir Welding, is presented. The Friction Surface Cladding (FSC) technology enables the deposition of a solid-state coating using filler material on a substrate with good metallurgical bonding. A relatively soft AA1050 filler material is deposited on a relatively hard AA2024-T351 substrate and the results are discussed. Depending on the process conditions, the filler material is deposited on top of the substrate or mixed through the surface region of the substrate. The cladded surface regions are analyzed using SEM-EDX, optical microscopy and micro hardness measurements to identify the resulting microstructure and establish the degree of mixing.
\end{abstract}

\section{Introduction}

Friction stir welding (FSW) is a relatively new solid-state joining technology for metals. It shows no solidification-related joint imperfections which makes it utmost suitable for hard-to-weld highly alloyed aerospace aluminium grades, like AA 2xxx and AA 7xxx. These alloys are often cladded with a thin layer of pure aluminium for corrosion protection. Friction stir wellding of such materials requires removal of the clad layer prior to welding to prevent weakening of the joint by the soft clad material. This leaves the welded region vulnerable to corrosion after the joining process. Post-weld restoration of the clad layer is required to restore the protective action of the clad layer and as such to enhance the life expectancy of the welded construction.

In this paper a solid state cladding process (Friction Surface Cladding, FSC) is presented that is related to FSW [1 - 3] and allows deposition of thin clad layers on a substrate through a hollow tool. The concept of a hollow FSW tool has been described before, mostly in patent literature $[4,5]$, but no results have been published up to now to the current knowledge of the authors. The cladding process combines (i) the heat generation due to friction by a rotating tool on a substrate surface and (ii) the deposition of surface layers similar to the Friction Surfacing (FS) technique $[6,7]$. A specially designed FSW tool with or without a central pin is provided with cylindrical channels that contain the filler material; see Fig. 1 for an example of a tool without a central pin.

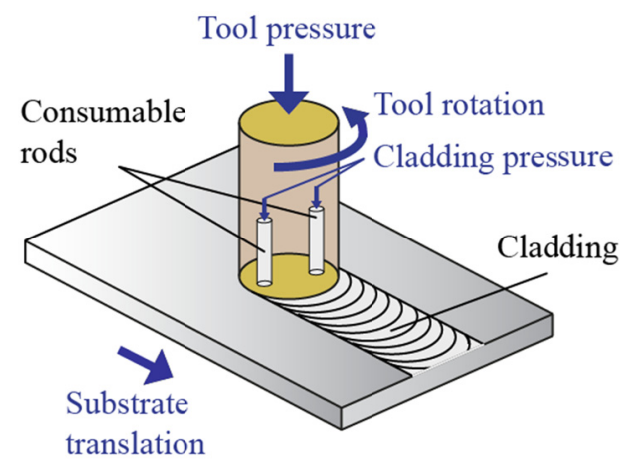

Figure 1. Schematic representation of friction surface cladding. 
During the process the consumable filler rods can be pushed outwards and as such provide the cladding material that is deposited onto the surface of the substrate. In this way the clad layer might be restored locally and the substrate would be protected against corrosion over its full surface.

In this work the deposition of relatively soft AA1050 filler material onto an AA2024-T351 substrate material has been explored and the influence of some process parameters has been studied.

\section{Friction Surface Cladding}

The presented friction surface cladding process is closely related to the friction surfacing process as both processes add a clad layer on a substrate [8]. The clad layers consist of plasticized layers of the consumable rods which are deposited by rotation under pressure. However, there are several differences. Firstly, friction surface cladding enables the controlled deposition of one or more consumable rods of equal or different materials, whereas friction surfacing consists of only one cylindrical rotating rod (mechtrode). Secondly, the filler rods do not need to rotate about their own axis and can move in an intricate manner with respect to the movement of the substrate intensifying the lateral distribution of the filler material, see Fig. 2a. In this way the lateral dimensions of the clad layer are larger than the diameter of the filler rods and mechtrode. Finally, the heat for softening and welding of the material is produced by friction of the filler material with the substrate, but, if the tool is tilted sufficiently with respect to the substrate (see Fig. 2b) also by the contact between the tool bottom surface and the substrate surface. The total heat generated thus consists of contributions from the friction between both the tool shoulder and the filler rods with the substrate.
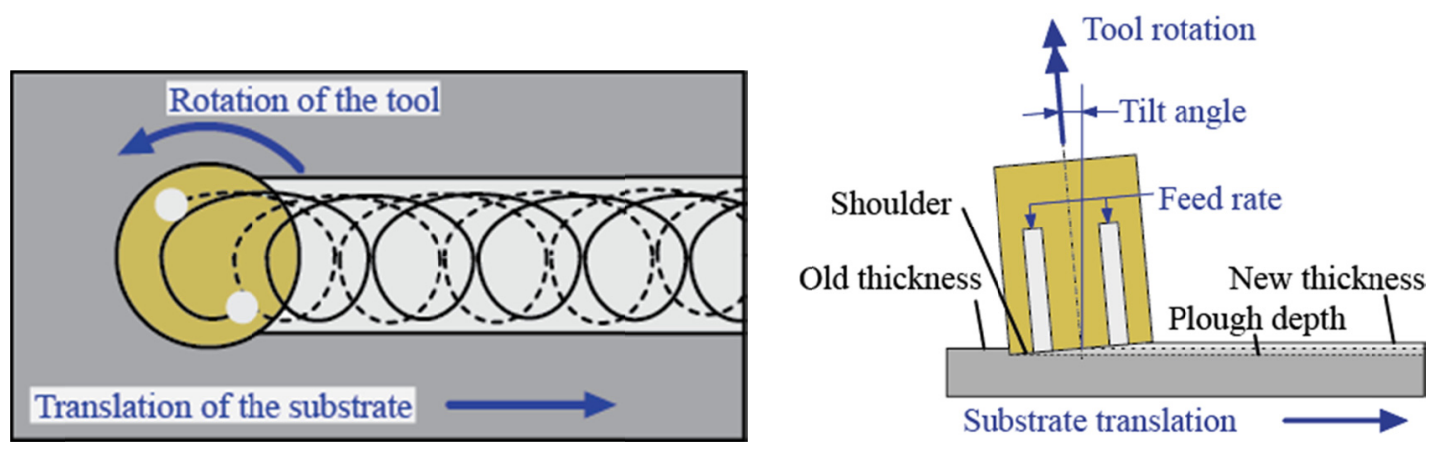

Figure 2. a) Top view of friction surface cladding with its cladding pattern and b) its side view.

The design of the FSC tool allows for independent control of the force exerted on the filler rods and the force exerted on the substrate by the tool shoulder. Depending on the level of both forces different regimes of cladding appear, as will be shown in the next sections. Furthermore, large scale flash formation, as often observed with friction surfacing $[9,10]$ is prevented by the presence of the tool shoulder, as it has a relatively large diameter compared to the filler rods. In this way a more efficient usage of filler material is accomplished. Finally, the hollow FSC tool can also be equipped with a central pin to perform FSW experiments with the possibility to add filler material for special applications. This will be the subject of future studies.

\section{Experimental setup}

The experiments were carried out on a modified planer machine that was equipped with a $13 \mathrm{~kW}$ powered FSW tool. The shoulder of the FSC tool contains two circular openings in the middle region of the tool to host the filler rods, as visible in Fig. 3. Here, two AA1050 filler rods will be used to deposit a thin clad layer on top of an AA2024-T351 substrate. The process parameters include tool rotation speed, substrate translation speed, tool tilt angle, the force exerted by the tool bottom on the substrate and the force applied to push out the filler rods. The total down force exerted on the substrate by the FSC tool is measured by load cells. The force exerted on the substrate by the tool prior to ejection of the filler rods is set by adjusting the tool height. During the 
translation phase of the tool, the tool height remains constant. The feed rate of the filler rods is not measured; the force exerted on the filler rods is determined instead.

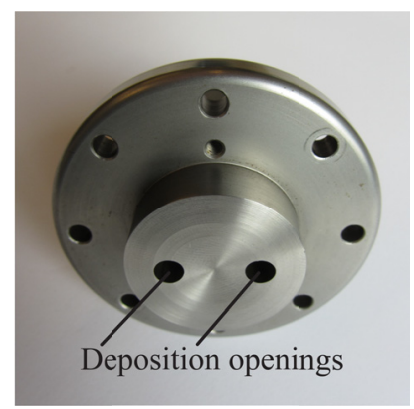

Figure 3. A friction surface cladding shoulder with deposition openings.

Two filler rods with a diameter of $5 \mathrm{~mm}$ are put in the cylindrical openings of the cladding tool located with an offset of $7.5 \mathrm{~mm}$ from its centre. The FSC shoulder is manufactured from H13 hardened steel and has a diameter of $30 \mathrm{~mm}$ with a conical edge. The filler material is deposited on a $300 \times 180 \mathrm{~mm}^{2}$ rectangular plate of $4 \mathrm{~mm}$ thickness. The substrate is clamped on a steel backing plate with steel clamps located at $65 \mathrm{~mm}$ at either side from the centre line of the weld.

\section{Experimental procedure}

The experiments start by lowering the rotating tool until the shoulder of FSC tool touches the surface of the substrate. After a sufficiently long dwell phase where the occurring friction heats up the substrate and the FSC tool, the filler supply system is switched on and the filler rods, while rotating, are pushed out towards the substrate. This forms the start of the deposition phase. Next, the substrate moves along the tool with a pre-defined speed. During this phase a coating is formed behind the tool until all filler rod material has been used. Finally, the filler supply system is stopped and the tool is pulled up which terminates the experiment. In this work the tool rotation speed, substrate travel speed and tool tilt angle are $600 \mathrm{RPM}, 30 \mathrm{~mm} \mathrm{~min}^{-1}$ and $+2.0^{\circ}$, respectively, for all experiments. The values of the forces exerted by the tool shoulder on the substrate and the force applied on the filler rods have been varied among the experiments.

\section{Microstructural analysis}

After the experiments, the plates were stored at room temperature for a minimum of two weeks to allow for post-weld aging processes to occur before they were machined. Specimens for microstructural observation of cross-sections of the weld were taken out using a band saw. Subsequently the samples were embedded in an epoxy resin such that the advancing side (AS) and retreating side (RS) are always on the right and left side of the cross section to be analyzed, respectively. In this case the top surface of the substrate remains above. The discs are mechanically grinded using through grit silicon papers up to grade 4000. Polishing was performed in three steps with a final polishing step using a colloidal silica suspension with a grain size of approximately $0.04 \mu \mathrm{m}$. The surfaces of the specimens were etched by Keller's reagent, consisting of $190 \mathrm{ml}_{2} \mathrm{O}$, $5 \mathrm{ml} \mathrm{HNO}_{3}$ (70\% concentrated), $3 \mathrm{ml} \mathrm{HCl}(37 \%)$ and $2 \mathrm{ml} \mathrm{HF}(40 \%)$.

The grain size distribution of the different regions of the weld were examined by optical microscopy. Hardness measurements were performed with an automatic microhardness measuring device employing a $0.98 \mathrm{~N}$ load and a 15 s loading time. A minimal distance of $200 \mu \mathrm{m}$ between the consecutive indents is used to prevent mutual interaction.

Finally, the elemental composition of selected regions of the weld were determined in a Scanning Electron Microscope employing Energy-Dispersive X-ray spectroscopy (SEM-EDX). 


\section{Results and discussion}

Cladding The first series of experiments was carried out with a relatively low total down force exerted on the substrate of $4.0 \mathrm{kN}$. The tool only partly touches the substrate material as the tool is tilted with respect to the substrate surface and an opening is present on the trailing edge of the tool. The force is significantly smaller than the sum of the forces exerted on the two cladding rods of 8.5 $\mathrm{kN}$, indicating that relatively large frictional forces exist/arise between the wall of the FSC tool and the filler rods in this case. Nevertheless, the filler rods are pushed outwards and a clad layer is deposited on the surface of the substrate material.

The macrostructure of a transverse cross section of the substrate material is shown in Fig. 4. Clearly, a thin layer with a different microstructure is present on the top surface of the AA2024T3 substrate. It has a width of approximately $21 \mathrm{~mm}$ and a thickness of about $0.5 \mathrm{~mm}$ in the middle. Some details of the microstructure of the clad layer can be seen in Fig. 5, where the strong orientation of crystals in a direction parallel to the substrate surface is evident. The fine grains indicate that the material is strongly mechanically deformed as a result of the compressive and rotating action of the FSC tool concomitantly pressing out the filler rods.

The elemental composition of part of the clad layer, as indicated by the black rectangle in Fig. 4, is determined with SEM-EDX. The microstructure of this region is shown in Fig. 6a, along with the $\mathrm{Cu}$ signals in Fig. 6b, that were determined at the same location. The different microstructures of the clad layer and the substrate material are well visible in Fig. 6a. The Cu signal can be used to identify the origin of the clad layer, as AA1050 virtually contains no $\mathrm{Cu}$ and AA2024 contains $\mathrm{Cu}$ between $3.8-4.9 \%$. The EDX measurement clearly shows a difference between the $\mathrm{Cu}$ signal in the clad layer and the substrate material. This strongly suggests that an almost pure AA1050 clad layer has been deposited on top of the substrate at this specific location. The results of the hardness measurements, as shown in Fig. 7, further support this suggestion, as the clad layer has a strongly lower hardness over its entire cross section than the AA2024 substrate material. The hardness distribution in the latter material is approximately symmetric about the centre. The decrease of the hardness of the substrate with respect to the material far away from the treated surface can mostly be explained from the evolution of temperature with time and place during the cladding process that affects the distribution and characteristics of the strengthening precipitates [11].

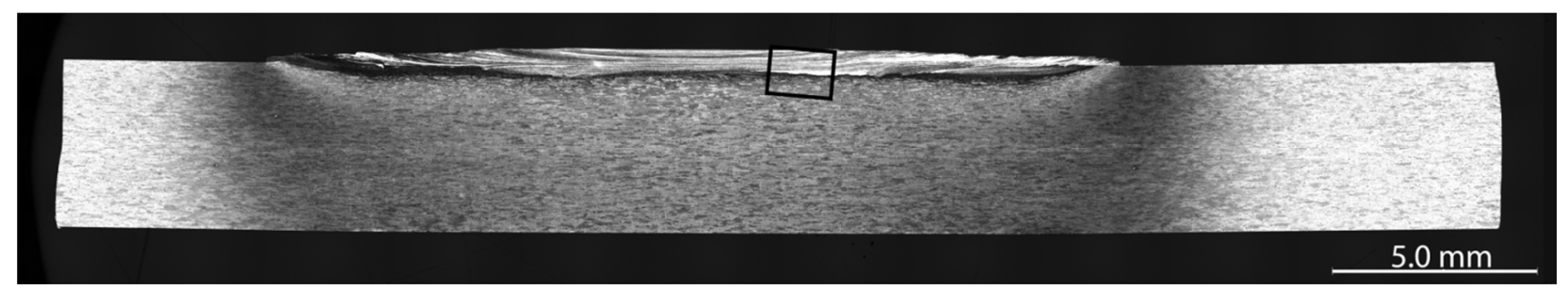

Figure 4. Macrostructure of the transverse cross section after the cladding experiment.
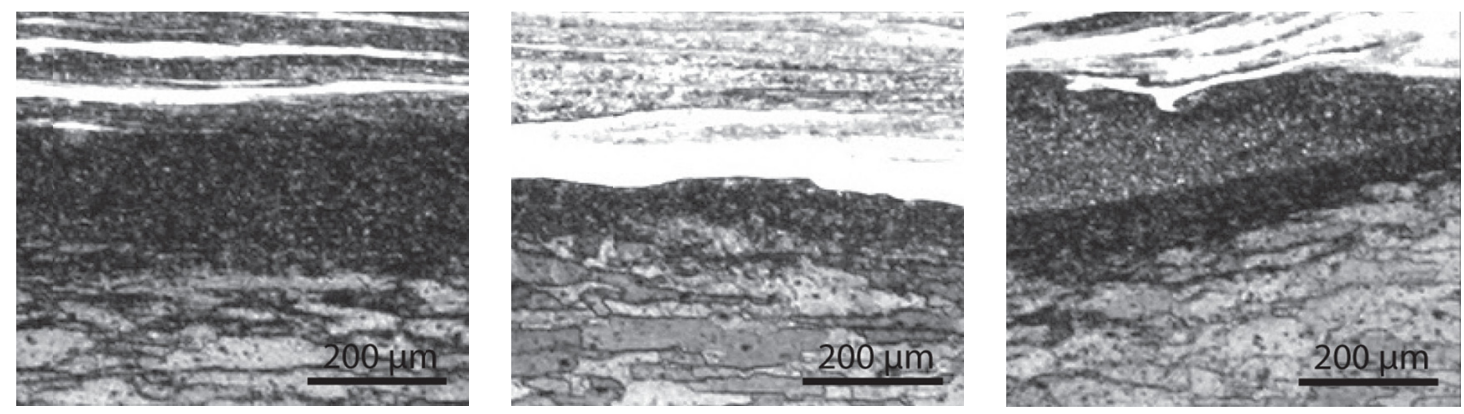

Figure 5. Microstructure of the transition area from the cladding layer to the substrate material at the a) RS, b) centre and c) AS. 

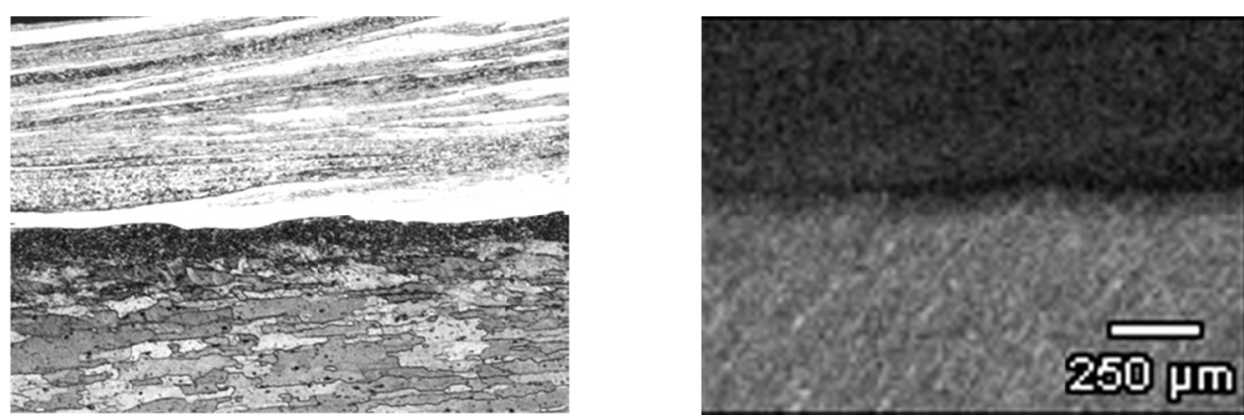

Figure 6. EDX measurement near the cladding layer indicated by the black rectangle in Fig. 4 showing a) the microstructure and b) $\mathrm{Cu}$ content.

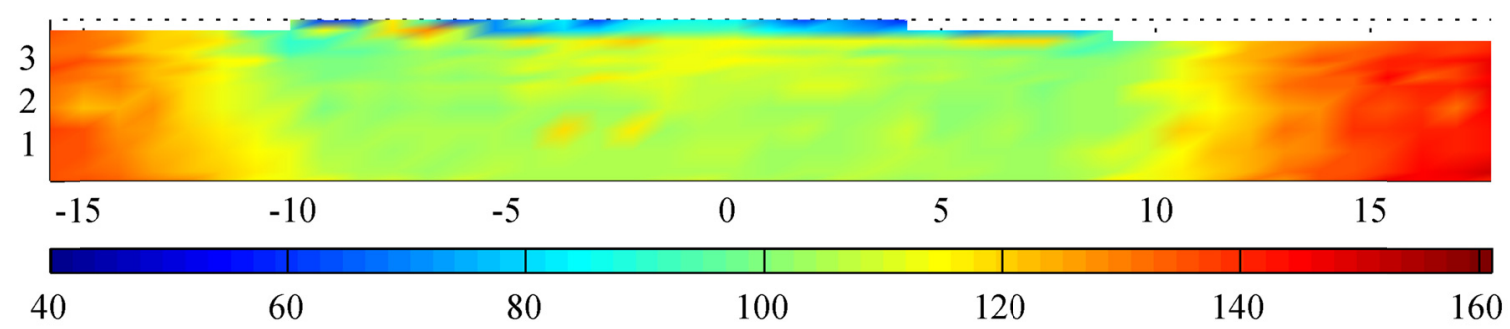

Figure 7. Hardness distribution of the cladded sample in Vickers scaled to Fig. 4.

Mixing The second series of experiments was carried out with a relatively large total down force exerted on the substrate of $15.0 \mathrm{kN}$. In this case, no space between the FSC tool shoulder and the substrate exists on the trailing side of the tool, forcing the filler material to be mixed with the substrate. It also increases the applied force on both filler rods up to $9.6 \mathrm{kN}$ in total.

The macrostructure of a cross section of the cladded substrate material is shown in Fig. 8. In comparison to Fig. 4, the extent of the modifications to the structure at the substrate surface is much larger. Although the width of the modified zone is comparable to the width of the clad layer in Fig. 4 , its depth is much larger with values between 1.7 and $2.3 \mathrm{~mm}$. Clearly, the large total down force exerted on the substrate material in combination with the addition of filler material has strong influences on the resulting macro and microstructure. EDX measurements were performed again within the refined grain region as indicated by the black rectangle in Fig. 8. The microstructure of this region is shown in Fig. 9a and the distribution of the $\mathrm{Cu}$ signal is depicted in Fig 9b. The EDX signal shows a lower distinction between $\mathrm{Cu}$ in the substrate and the modified zone, which suggests that mixing of the AA1050 filler rods with the AA2024 substrate material has indeed occurred. The hardness measurements shown in Fig. 10 also support this idea, since the hardness in the modified zone in the top layer of the substrate material is substantially higher than in Fig. 7, which can only be explained by the presence of substantial amounts of relatively hard substrate material.

An interesting aspect is the relatively high hardness values measured in the centre region of the substrate material below the modified zone. The hardness values are similar to the original hardness before the cladding treatment. The temperature evolution in the centre region has a strong influence on the size and distribution of the strengthening precipitates. According to Jones [11] growth and re-precipitation phenomena can occur during the heating and cooling stages of FSW of AA2024-T351 alloy. These relatively high hardness values occurring in AA2024 after friction stir welding under similar conditions were confirmed by Khodir [12-13]. Here, similar temperature changes occur which can explain the restoration of the original hardness in the centre region and the decrease of the hardness further away from the centre region (heat affected zone). 


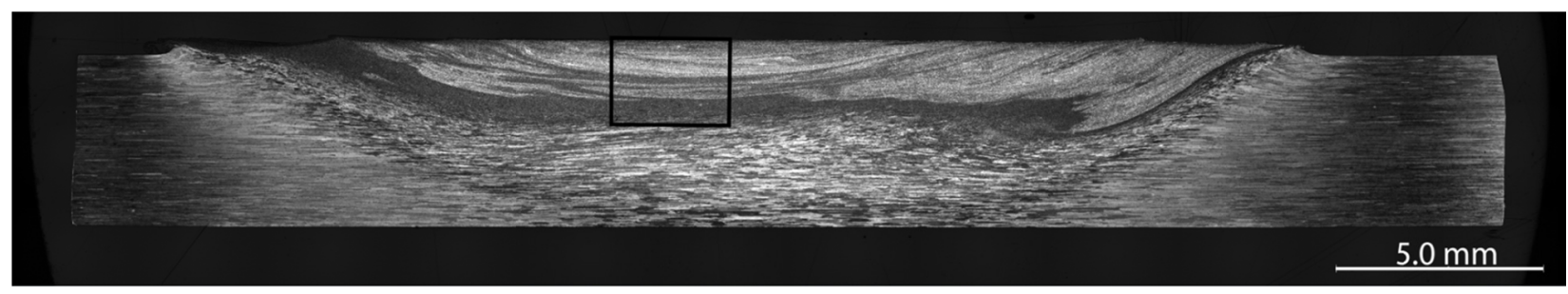

Figure 8. Macrostructure of the transverse cross section after the mixing experiment.
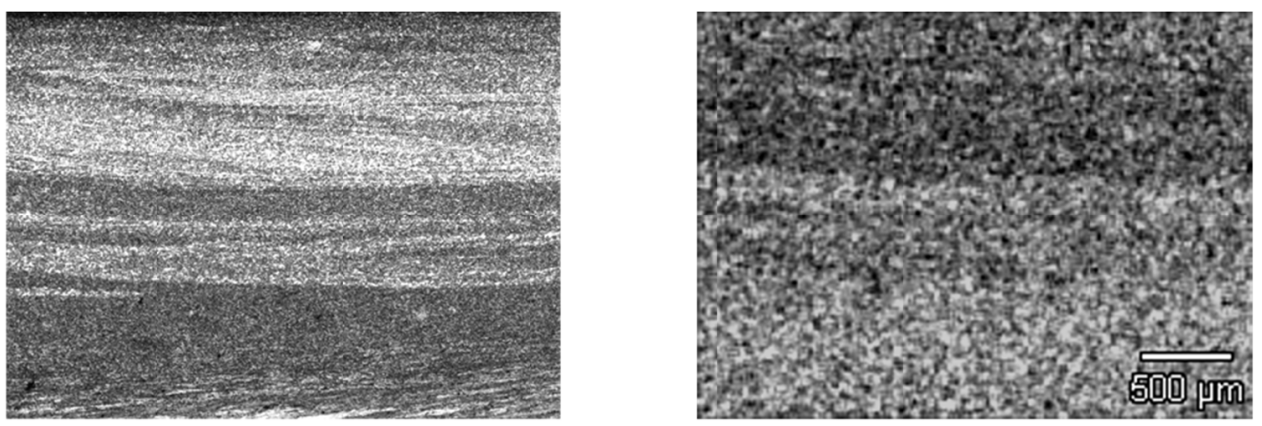

Figure 9. EDX measurement near the mixing layer indicated by the black rectangle in Fig. 8 showing a) the microstructure and b) Cu content.

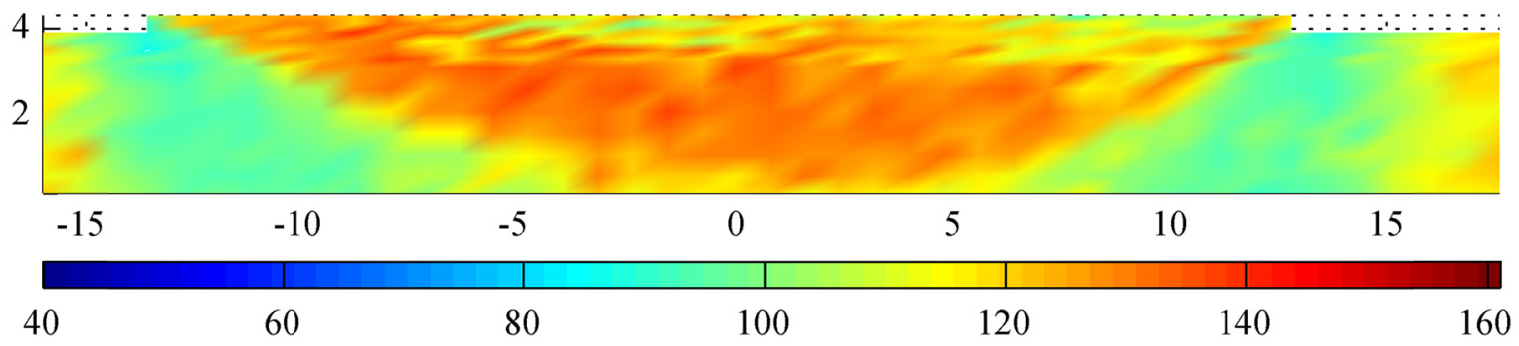

Figure 10. Hardness distribution of the mixed sample in Vickers scaled to Fig. 8.

Hardness difference The hardness distributions of cross sections after the cladding and mixing experiments differ significantly as shown in Fig. 7 and 10. Near the top surface of the cladded material a discontinues change in hardness is visible as opposed to the top surface of the mixed material. A more detailed view on the change of the hardness through the thickness of the substrate is shown in Fig. 11. It shows the average hardness of the substrate of centre regions of the cross sections. For the cladded material the hardness values between -3.8 and $1.8 \mathrm{~mm}$ from the centreline have been selected (see Fig. 7), for the mixed material between -5.6 and $-0.8 \mathrm{~mm}$ (see Fig. 10).

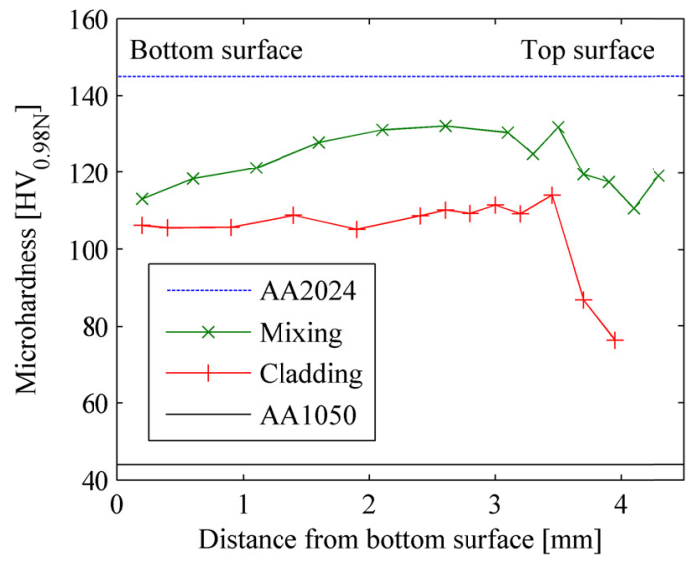

Figure 11. Average hardness distribution through the thickness of the substrate for cladding and mixing in the centre region of the substrate. 
The hardness values of the cladded material in the centre region remain approximately constant from the bottom of the substrate up to $3.5 \mathrm{~mm}$ and, then, decrease strongly down to below $80 \mathrm{HV}$ in between 3.5 and $4.0 \mathrm{~mm}$ indicating the relatively low hardness and strength of the deposited clad layer. For the mixed material case, the hardness remains closer to the hardness of the fresh base material and no rapid decrease is observed near the top surface. However, there is tendency towards greater variation in the hardness values near the top surface that complies with the banded nature of the microstructure as observed in Fig. 9a and b. The variation indicates that the addition of AA1050 in the mixed layer lowers the hardness at this specific location. The addition of AA1050 can be seen in Fig. 9b showing darker bands which contains less copper. Apparently, the friction surface cladding experiment with the current experimental settings causes considerable mixing of the substrate and the filler material, but up to a certain degree.

\section{Conclusions}

In this paper the first results of the Friction Surface Cladding (FSC) process, that is related to friction stir welding, have been presented. Based on the observed microstructure, micro hardness and SEM-EDX measurements it has been demonstrated that FSC is capable of deposition of a thin AA1050 clad layer on an AA2024-T351 substrate. By changing the experimental conditions the filler material can also be mixed with the surface region of the substrate material. As such, the FSC process expands the possibilities to clad and/or mix materials on a substrate in the solid state.

\section{Acknowledgements}

This research was carried out under project number MC8.07290 in the framework of the Research Program of the Materials innovation institute M2i (www.m2i.nl).

\section{References}

[1] W.M. Thomas, E.D. Nicholas, J.C. Needham, M.G. Murch, P. Templesmith, and C.J. Dawes, Friction stir but welding, G.B. Patent 9125978.8 (1991).

[2] R.S. Mishra and M.W. Mahoney, Friction stir welding and processing, ASM International (2007).

[3] D. Lohwasser and Z. Chen, Friction stir welding: From basics to applications, Woodhead Publishing Ltd (2009).

[4] G.J. Bruck, M. Ott, D.W. Hunt and P.M. Georgieva, Filler rotated friction stir welding, U.S. Patent No. 8.066.174 B2 (2011).

[5] S.H. Fujii, O. Fukusumi, O. Morisada and Y. Ishikawa, Process for working metal material and structures, U.S. Patent No. 7.918.379 B2 (2011).

[6] H. Klopstock and A.R. Neelands, An improved method of joining and welding metals, U.K. Patent No. 572789 (1941).

[7] G.M. Bedford, Friction surfacing for wear applications, Metals and materials 611 (1990) 702705 .

[8] K.P. Rao, A. Sankar, H.K. Rafi, G.D.J. Ram, G.M. Reddy, Friction surfacing on nonferrous substrates: a feasibility study, International journal of advanced manufacturing technology (May 2012).

[9] U. Suhuddin, S. Mironov, H. Krohn, M. Beyer, and J. F. Dos Santos. Microstructural Evolution During Friction Surfacing of Dissimilar Aluminum Alloys, Metallurgical and Materials Transactions A (August 2012). 
[10] J. Gandra, R.M. Miranda, and P. Vilac, a. Performance analysis of friction surfacing, Journal of Materials Processing Technology, 2128 (2012) 1676-1686.

[11] M.J. Jones, P. Heurtier, C. Desrayaud, F. Montheillet, D. Allehaux and J.H. Driver, Correlation between microstructure and microhardness in friction stir welded 2024 aluminium alloy, Scripta materialia 52 (2005) 693-697.

[12] S.A. Khodir, T. Shibayanagi and M. Naka, Microstructure and mechanical properties of friction stir welded AA2024-T3 aluminium alloy, Material transactions 471 (2006) 185-193.

[13] S.A. Khodir, T. Shibayanagi and M. Naka, Control of hardness distribution in friction stir welded AA2024-T3 aluminium alloy, Material transactions 476 (2006) 1560-1567. 